\title{
Clinical effects of three surgical approaches for a giant cell tumor of the distal radius and ulna
}

\author{
JING ZHANG $^{1 *}$, YI LI $^{2 *}$, DONGQI LI ${ }^{1 *}$, JUNFENG XIA $^{1 *}$, SU LI $^{1}$, SHUNLING YU ${ }^{1}$, \\ YEDAN LIAO ${ }^{1}$, XIAOJUAN LI $^{1}$, HUILIN LI ${ }^{1}$ and ZUOZHANG YANG ${ }^{1}$ \\ ${ }^{1}$ Department of Orthopedics, The Third Affiliated Hospital of Kunming Medical University, Tumor Hospital of Yunnan;
${ }^{2}$ Department of Oncology, Kunming General Hospital of Chengdu Military Command, Kunming, Yunnan 650118, P.R. China
}

Received October 29, 2015; Accepted September 6, 2016

DOI: $10.3892 / \mathrm{mco} .2016 .1031$

\begin{abstract}
The aim of the present study was to assess the curative effects of three surgical approaches for a giant cell tumor (GCT) of the distal radius and ulna. A total of 27 patients with GCT on distal radius and ulnas (7 and 20, respectively), confirmed by biopsy, were treated with individualized treatment regimens, according to the Campanacci's grade system: i) Curettage plus inactivated tumor bed and allogeneic bone graft/bone cement augmentation for Campanacci's grade I GCT of the distal radius and ulna (Group A); ii) simple en bloc resection for Campanacci's grade II and III GCT of the distal ulna (Group B); iii) en bloc resection and reconstruction with non-vascularized fibular autograft/allogeneic bone graft for Campanacci's II and III GCT of the distal radius (Group C). Postoperative recurrence and complications were recorded. The Musculoskeletal Tumor Society Score was used to assess functional results. The mean follow-up time was 25 months (range, 9-125 months). A total of 3 patients exhibited tumor recurrence at 9, 11 and 15 months following surgery (1 case succumbed to pulmonary metastasis at 27 months). Overall, the incidence of the postoperative recurrence of the GCT of the distal ulna and radius were $14.3(1 / 7)$ and $10 \%(2 / 20)$, respectively, with a statistical P-value of 0.762 . No statistically significant difference was observed regarding the incidence of the postoperative recurrence, postoperative complications and MSTS results among the three surgical approaches for the GCT on distal ulna and radius (all $\mathrm{P}>0.05$ ). However, statistically significant differences were noted when the incidence of the postoperative recurrence of curettage (Group A) was
\end{abstract}

Correspondence to: Dr Zuozhang Yang, Department of Orthopedics, The Third Affiliated Hospital of Kunming Medical University, Tumor Hospital of Yunnan, 519 Kunzhou Road, Kunming, Yunnan 650118, P.R. China

E-mail: yangzuozhang88@yeah.net

*Contributed equally

Key words: giant cell tumor of bone, distal radius, distal ulna, surgical therapy compared with that of en bloc resection (Groups B and C) $(\mathrm{P}=0.024)$. In conclusion, in order to achieve the best clinical effects for patients with GCT on distal radius and ulna, individualized treatment regimens must be designed according to the different Campanacci's grades and tumor locations.

\section{Introduction}

Giant cell tumor (GCT) of the bone represents $\sim 5 \%$ of primary bone tumor types and $20 \%$ of benign bone tumor types (1). The disease often occurs in adults between the ages of 20 - and 40-years-old, with a higher incidence in females $(2,3)$. GCTs are generally composed of mononuclear histiocytic cells, multinucleated giant cells resembling osteoclasts and neoplastic stromal cells that are the predominant proliferating cell population $(4,5)$. The disease is generally recognized as a border or low-grade, with a certain degree of invasive characteristics, demonstrated by biological behavior $(6,7)$. The predominant problem in the management of GCT is local recurrence following surgical treatment: $27-65 \%$ following isolated curettage; $12-27 \%$ following curettage with adjuvants such as high-speed burr, phenol, liquid nitrogen, or polymethylmethacrylate; and 0-12\% after en bloc resection (6).

The distal radius and ulna is the fourth most common location for GCT of the bone, after the distal femur, proximal tibia and proximal femur, accounting for $\sim 9 \%$ of cases $(8,9)$. Numerous previous studies have identified the distal radius and ulna as being particularly prone to recurrence. To date, the ideal treatment methods for GCTs of the distal ulna and radius remain controversial (10-12). En bloc resection of GCT provides lower rates of recurrences, which also sacrifices the joint, results in a major reconstruction, and the functional outcomes are questionable. Intralesional excision (curettage) preserves the joint; however, has a reasonably high risk of local recurrence even if used in combination with surgical adjuvants, including liquid nitrogen, phenol or cement $(8,10,13)$. Therefore, the effect of different surgical modalities on tumor recurrence and postoperative wrist function remains unclear. The aim of the present study was to assess the clinical effects of three surgical approaches for GCT of the distal radius and ulna, including curettage plus inactivated tumor bed plus allogeneic bone graft/bone cement augmentation, simple en bloc resection, and en bloc resection and reconstruction 
with non-vascularized fibular autograft/allogeneic bone graft segment.

\section{Materials and methods}

Patients. The present study was approved by the Ethics Committee of the Tumor Hospital of Yunnan Province and was performed in accordance with the declaration of Helsinki. Informed consent was obtained from all patients. The present study retrospectively collected the clinical data of patients with a GCT of the distal radius and ulna between January 2000 and December 2013. The inclusion criteria were patients who were diagnosed with GCT by biopsy examination in The Third Affiliated Hospital of Kunming Medical University, Tumor Hospital of Yunnan Province and confirmed the location as the distal radius and ulna by $\mathrm{X}$-ray and computed tomography. The exclusion criteria were as follows: i) Patients with a previous history of surgery; ii) patients receiving surgical treatment other than the three surgical methods being assessed; iii) patients who received non-surgical treatment.

Surgical points. Individual therapeutic regimens were selected according to the Campanacci's grade (14) and the location of distal ulna and radius (Table I). The key points included: Following curettage, a Stryker drill (Stryker, Kalamazoo, MI, USA) was used to grind lesions along each direction. Then, 95\% ethanol was used to inactivate the tumor bed. For en bloc resection, the scope of the osteotomy was determined by the preoperative imaging results. It is usually no less than $2 \mathrm{~cm}$ distance to the focus, including soft tissue reaction zone or soft tissue focus. The present study used autologous fibular graft or allogeneic bone graft segment (contained distal articular surface) to reconstruct the radiocarpal joint (Fig. 1).

Functional assessment. The Musculoskeletal Tumor Society Score (MTSS) was used to assess limb function (15). The system consisted of six items, including pain, overall function, psychological level, gesture, sensitivity and muscle strength. The functional result was assessed as excellent (30-24 scores), good (23-18 scores), fair (17-12 scores) or poor ( $<12$ scores) using the grading scheme.

Statistical analysis. The mean follow-up time of the 27 patients was 25 months (range, 9-125 months). All data were analyzed using SPSS 19.0 software (IBM SPSS, Chicago, IL, USA). Continuous variables were expressed in terms of means \pm standard deviation and were compared using a one-way analysis of variance. Categorical variables were expressed in terms of percentage and frequency, and were compared using the $\chi^{2}$ test. $\mathrm{P}<0.05$ was considered to indicate a statistically significant difference.

\section{Results}

Preoperative patients' characteristics. From January 2000 to December 2013, a total of 27 patients with GCT of the distal radius and ulna were included. The patients consisted of 10 male and 17 female. The mean age was 34.8-years-old
Table I. Baseline characteristics of 27 patients with a giant cell tumor on the distal radius and ulna.

\begin{tabular}{lc}
\hline Characteristic & No. patients \\
\hline Mean age, years (range) & $34.8(21-72$-years-old) \\
Gender (male/female) & $10 / 17$ \\
Location (distal ulna/distal radius) & $7 / 20$ \\
Campanacci's Grade & \\
Grade I & 4 \\
Grade II & 16 \\
Grade III & 7 \\
MSTS scores (range) & $20(11-28)$ \\
Surgical regimens & \\
Group A & 4 \\
Group B & 5 \\
Group C & 18 \\
Preoperative soft-tissue invasion & 7 \\
Preoperative pathological fracture & 5 \\
Tumor size & \\
$\geq 3$ cm & 22 \\
$<3$ cm & 5 \\
Follow-up time, months (range) & \\
\end{tabular}

Group A, curettage, inactivated tumor bed and allogeneic bone graft/ bone cement augmentation; Group B, simple en bloc resection; Group $\mathrm{C}$, en bloc resection and reconstruction with non-vascularized fibular autograft/allogeneic bone graft; MSTS, Musculoskeletal Tumor Society Score.

(range, 21-72-years-old). The tumor location was the distal ulna in 10 cases and the distal radius in the remaining 17 cases. The GCT was graded radiologically according to Campanacci et al (14). According to Campanacci's grading system, 4 cases were in stage I, 16 cases in stage II and 7 cases in stage III. The clinical data of the patients are shown in Table II.

Postoperative recurrence. A total of 3 patients (11.1\%) exhibited tumor recurrence at 9, 11 and 15 months after surgery. The case with Campanacci's grade I GCT of the distal radius exhibited tumor recurrence 9 months after curettage plus inactivated tumor bed plus bone cement augmentation. The case with Campanacci's grade I GCT of distal ulna exhibited recurrance 11 months after curettage plus inactivated tumor bed plus bone cement augmentation. The two patients were treated with en bloc resection and reconstruction with allogeneic bone graft segment after pathological examination and developed no recurrence after the aforementioned secondary surgery. The remaining case with Campanacci's grade III GCT of distal radius exhibited tumor recurrence 15 months after en bloc resection and reconstruction with allogeneic bone graft segment. The patient was further treated with en bloc resection and reconstruction with autologous fibular graft. At 6 months postoperatively, the patient developed pulmonary metastasis and succumbed to respiratory failure 
Table II. Individualized surgical methods according to Campanacci's grade of giant cell tumor of the distal ulna and radius.

Campanacci's classification

$\begin{array}{llll}\text { Tumor location } \quad \text { Grade I } & \text { Grade II }\end{array}$

\begin{tabular}{|c|c|c|c|}
\hline Distal ulna & $\begin{array}{l}\text { Curettage, inactivated tumor bed } \\
\text { and allogeneic bone graft/bone } \\
\text { cement augmentation (Group A) }\end{array}$ & Simple en bloc resection (Group B) & $\begin{array}{l}\text { Simple en bloc resection } \\
\text { (Group B) }\end{array}$ \\
\hline Distal radius & $\begin{array}{l}\text { Curettage, inactivated tumor bed } \\
\text { and allogeneic bone graft/bone } \\
\text { cement augmentation (Group A) }\end{array}$ & $\begin{array}{l}\text { En bloc resection and autologous } \\
\text { fibular graft/llogeneic bone graft } \\
\text { segment (Group C) }\end{array}$ & $\begin{array}{l}\text { En bloc resection and autologous } \\
\text { fibular graft/llogeneic bone graft } \\
\text { segment (Group C) }\end{array}$ \\
\hline
\end{tabular}
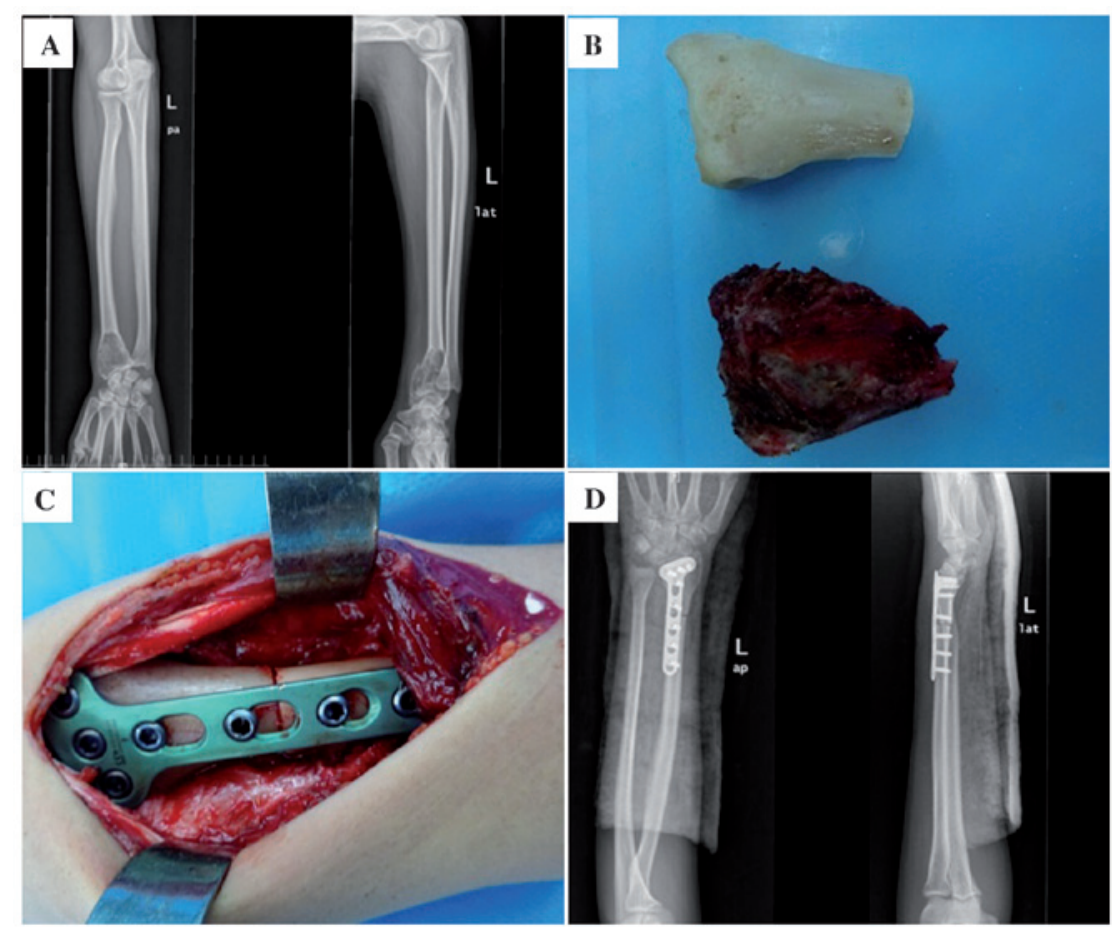

Figure 1. A 21-year-old female with Campanacci's grade III giant cell tumor of the distal radius on the left side and pathological fracture. The patient was treated with distal radial tumor segment resection, allogeneic bone segment graft and plate-screw internal fixation. (A) Preoperative anteroposterior (left) and lateral X-ray (right) examination revealed bone destruction and pathological fracture of the left distal radius. (B) The resected tumor segment of radius and trimmed allogeneic bone segment. (C) Postoperative photo following surgery. (D) Postoperative anteroposterior (left) and lateral (right) radiographs.

after chemotherapy and supportive therapy for 6 months. Overall, the incidence of the postoperative recurrence of the GCT of the distal ulna and radius was $14.3(1 / 7)$ and $10 \%(2 / 20)$, respectively, with a statistical P-value of 0.762 . The incidence of the postoperative recurrence were $50 \%$ $(2 / 4)$ in Group A, 0\% (0/5) in Group B and 5.6\% (1/18) in Group C, with a statistical P-value of 0.069 . However, statistical significance was noted when the incidence of the postoperative recurrence of curettage (Group A) was compared with that of en bloc resection (Groups B and C) (50 vs. $4.3 \%$; $\mathrm{P}=0.024$ ).

Postoperative complications. Of the patients, 4/27 (14.8\%) with GCT of the distal radius developed postoperative complications, including 1 case of postoperative infection, 2 cases of implant breakage and postoperative fractures, and 1 case of nonunion (Table III). No statistically significant difference was observed regarding the incidence of the postoperative complications among the three surgical approaches for the GCT on the distal ulna and radius $(\mathrm{P}>0.05)$. The patient who developed postoperative infection healed following anti-infection drug therapy. The remaining 3 patients underwent secondary fibulo-scapholunate arthrodesis, and no postoperative infection or nonunion was noted. None of the patients developed neurovascular complications.

Function outcomes. The mean follow-up time of the 27 patients was 25 months (range, 9-125 months). Functional MTSS results were excellent in 7 cases $(25.9 \%)$, good in 12 cases $(44.5 \%)$, fair in 5 cases $(18.5 \%)$ and poor in 3 cases $(11.1 \%)$. The overall excellent and good rate was $70.4 \%$ (Table III). No statistically significant difference was 
Table III. Postoperative outcomes in the three groups.

\begin{tabular}{lcccc}
\hline Outcome & Group A (n=4) & Group B (n=5) & Group C (n=18) & P-value \\
\hline Recurrence & $2(50 \%)$ & $0(0 \%)$ & $1(5.6 \%)$ & $0.024^{\mathrm{a}}$ \\
Infection & $0(0 \%)$ & $0(0 \%)$ & $1(5.6 \%)$ & 0.660 \\
Internal fixation fracture & $0(0 \%)$ & $0(0 \%)$ & $2(11.1 \%)$ & 0.427 \\
Nonunion & $0(0 \%)$ & $0(0 \%)$ & $1(5.6 \%)$ & 0.660 \\
Functional assessment & & & & \\
Excellent & $2(50 \%)$ & $2(40 \%)$ & $3(16.7 \%)$ & 0.397 \\
Good & $0(0 \%)$ & $2(40 \%)$ & $10(55.5 \%)$ & \\
Fair & $1(25 \%)$ & $1(20 \%)$ & $3(16.7 \%)$ & \\
Poor & $1(25 \%)$ & $0(0 \%)$ & $2(11.1 \%)$ & \\
\hline
\end{tabular}

${ }^{a}$ Group A vs. Group B and C.

observed regarding the postoperative MTSS results among the three surgical approaches for the GCT on the distal ulna and radius.

\section{Discussion}

Currently, no consensus has been reached regarding the optimal treatment approach for GCTs that occur in the distal radius. Although almost $100 \%$ local control can be achieved with en bloc resection (16), limb function is usually offset (17). Intralesional excision with curettage is the standard method of treatment; however, it is associated with the rates of local recurrence ranging between 10 and 40\% (18-21). As a result, topical adjuvant agents, including hydrogen peroxide, phenol and alcohol, have been used to decrease the recurrence rates (9). Liu et al (10) reported that patients in the intralesional excision group exhibited a higher recurrence rate, particularly for Campanacci's III Grade GCT compared with the en bloc resection group (10). Pazionis et al (11) reported that the odds of local recurrence were three times less in the en bloc resection group $(n=60)$ compared with the intralesional excision group $(n=81)$. Considering the high local recurrence risk of curettage, the 23 patients with Campanacci's grade II and III GCT of the distal radius and ulna were all treated with en bloc resection, and only one patient $(1 / 23 ; 4.3 \%)$ relapsed. However, 6 months after secondary surgery, the patient developed pulmonary metastasis, which may be associated with the high invasiveness. Considering the limited lesions of Campanacci's grade I GCT, the present study selected the curettage plus inactivated tumor bed and allogeneic bone graft (1 case)/bone cement augmentation (3 cases) for Campanacci's grade I GCT of the distal radius and ulna, which can theoretically guarantee the safety boundary. However, the incidence of the postoperative recurrence of patients was $50 \%(2 / 4)$, which is higher compared with that reported previously, which may be due to limited sample size. It can also partially reflect that the application of bone cement augmentation cannot reduce the risk of the recurrence of GCT (9). A previous report suggested that wrist joint can still reach $75 \%$ grasp strength and $80 \%$ range of motion following distal ulnar resection (22). Therefore, in the present study, en bloc resection without reconstruction for Campanacci's grade II and III GCT of the distal ulna was selected. Following surgery, no statistically significant difference was revealed regarding the incidence of the postoperative recurrence of the GCT in distal ulna and radius (14.3 vs. 10\%). Although no statistically significant difference was found in the present study regarding the incidence of the postoperative recurrence among the three surgical approaches for the GCT on distal ulna and radius, a $>10$-fold higher difference was revealed regarding the incidence of the postoperative recurrence of curettage when compared with that of en bloc resection. Further studies with a larger number of samples are warranted.

Various surgical approaches for GCT of the distal radius and ulna can produce different rates of postoperative complications. Previous reports suggested that en bloc resection was associated with a relatively high rate of major complications (range, 29-100\%) (23-27). These complications included nonunion at the graft-radius junction (12-38\%) (26-28), fracture of graft (13-29\%) $(26,27)$, subluxation $(12-67 \%)(23,26)$, arthritis $(13-50 \%)(23,28)$ and postsurgical pneumonia (24). Notably, in the present study, 1 case $(5.6 \%)$ experienced postoperative infection, which may be associated with rich blood supply and rapid tissue healing. Additionally, 2 cases of internal fixation fracture (11.2\%) and 1 case of nonunion (5.6\%) occurred. These patients received reconstruction with allogeneic bone graft. This may be associated with the slow creeping substitution of allografts and premature functional exercise. These 3 patients underwent with fibulo-scapholunate arthrodesis and thereafter no postoperative infection or nonunion was noted. Overall, the postoperative complications observed in the present study were lower compared with that in the aforementioned reports.

Patients with GCT of the distal radius and ulna can have long-term survival, unless the incidence of pulmonary metastasis occurs; therefore, functional recovery of the wrist is extremely important. In the present study, patients undergoing allogeneic bone graft were all treated with individual customized allografts with the preservation of the articular aspect of the distal radius. The overall excellent and good rate 
of en bloc resection and reconstruction was $70.4 \%$, which is not statistically different compared with that of curettage. The present study suggested that en bloc resection and reconstruction can be used as the standard initial treatment method for Campanacci's grade II and III GCT. Wysocki et al (12) suggested that curettage can be considered for the initial treatment for Campanacci's grade II and III GCT of the distal radius, since en bloc resection can be performed if tumor recurrence occurred. However, secondary surgery not only increases the expense of the patients, it also increases the risk of postoperative complications. Therefore, the present study suggested that en bloc resection can be used as the standard initial treatment method for Campanacci's grade II and III GCT, whereas curettage can be used for Campanacci's I Grade GCT.

In conclusion, in order to achieve the best clinical effects for patients with GCT on distal radius and ulna, individualized treatment regimens must be designed according to the different Campanacci's grades and tumor locations.

\section{Acknowledgements}

The present study was supported in part by the National Natural Science Foundation of China (grant no. 81302343), the Joint Special Funds for the Department of Science and Technology of Yunnan Province-Kunming Medical University (grant no. 2014FB067), and the Doctor Funds Project of Tumor Hospital of Yunnan province (grant no. BSJJ201501).

\section{References}

1. Vanni D, Pantalone A, Andreoli E, Caldora P and Salini V: Giant cell tumor of the distal ulna: A case report. J Med Case Rep 6 : $143,2012$.

2. Raskin KA, Schwab JH, Mankin HJ, Springfield DS and Hornicek FJ: Giant cell tumor of bone. J Am Acad Orthop Surg 21: 118-126, 2013.

3. Padwa BL: Giant cell tumor. In: Pediatric Head and Neck Tumors. Rahbar R, Rodriguez-Galindo C, Meara JG, Smith ER, and Perez-Atayde AR (eds). Springer-Verlag, New York, NY, pp165-170, 2014

4. Werner M: Giant cell tumour of bone: Morphological, biological and histogenetical aspects. Int Orthop 30: 484-489, 2006.

5. Klenke FM, Wenger DE, Inwards CY, Rose PS and Sim FH: Giant cell tumor of bone: Risk factors for recurrence. Clin Orthop Relat Res 469: 591-599, 2011.

6. Chakarun CJ, Forrester DM, Gottsegen CJ, Patel DB, White EA and Matcuk GR Jr: Giant cell tumor of bone: Review, mimics, and new developments in treatment. Radiographics 33: 197-211, 2013.

7. Balke M, Schremper L, Gebert C, Ahrens H, Streitbuerger A, Koehler G, Hardes J and Gosheger G: Giant cell tumor of bone: Treatment and outcome of 214 cases. J Cancer Res Clin Oncol 134: 969-978, 2008.

8. Errani C, Ruggieri P, Asenzio MA, Toscano A, Colangeli S, Rimondi E, Rossi G, Longhi A and Mercuri M: Giant cell tumor of the extremity: A review of 349 cases from a single institution. Cancer Treat Rev 36: 1-7, 2010.

9. Niu X, Zhang Q, Hao L, Ding Y, Li Y, Xu H and Liu W: Giant cell tumor of the extremity: retrospective analysis of 621 Chinese patients from one institution. J Bone Joint Surg Am 94: 461-467, 2012.
10. Liu YP, Li KH and Sun BH: Which treatment is the best for giant cell tumors of the distal radius? A meta-analysis. Clin Orthop Relat Res 470: 2886-2894, 2012.

11. Pazionis TJ, Alradwan H, Deheshi BM, Turcotte R, Farrokhyar F and Ghert M: A Systematic review and meta-analysis of En-Bloc vs intralesional resection for giant cell tumor of bone of the distal radius. Open Orthop J 7: 103-108, 2013.

12. Wysocki RW, Soni E, Virkus WW, Scarborough MT, Leurgans SE and Gitelis S: Is intralesional treatment of giant cell tumor of the distal radius comparable to resection with respect to local control and functional outcome? Clin Orthop Relat Res 473: 706-715, 2015.

13. Prosser GH, Baloch KG, Tillman RM, Carter SR and Grimer RJ: Does curettage without adjuvant therapy provide low recurrence rates in giant-cell tumors of bone? Clin Orthop Relat Res 211-218, 2005.

14. Campanacci M (ed): Bone and Soft Tissue Tumors: Clinical Features, Imaging, Pathology and Treatment. Springer-Verlag, Vienna, Austria, 1999

15. Enneking WF, Dunham W, Gebhardt MC, Malawar M and Pritchard DJ: A system for the functional evaluation of reconstructive procedures after surgical treatment of tumors of the musculoskeletal system. Clin Orthop Relat Res 241-246, 1993.

16. Su YP, Chen WM and Chen TH: Giant-cell tumors of bone: An analysis of 87 cases. Int Orthop 28: 239-243, 2004.

17. Gitelis S, Mallin BA, Piasecki P and Turner F: Intralesional excision compared with en bloc resection for giant-cell tumors of bone. J Bone Joint Surg Am 75: 1648-1655, 1993.

18. Blackley HR, Wunder JS, Davis AM, White LM, Kandel R and Bell RS: Treatment of giant-cell tumors of long bones with curettage and bone-grafting. J Bone Joint Surg Am 81: 811-820, 1999.

19. Lausten GS, Jensen PK, Schiødt T and Lund B: Local recurrences in giant cell tumour of bone. Local-term follow up of 31 cases. Int Orthop 20: 172-176, 1996

20. Malek F, Krueger P, Hatmi ZN, Malayeri AA, Faezipour H and O'Donnell RJ: Local control of long bone giant cell tumour using curettage, burring and bone grafting without adjuvant therapy. Int Orthop 30: 495-498, 2006.

21. Kivioja AH, Blomqvist C, Hietaniemi K, Trovik C, Walloe A, Bauer HC, Jorgensen PH, Bergh $\mathrm{P}$ and Follerås G: Cement is recommended in intralesional surgery of giant cell tumors: A Scandinavian Sarcoma Group study of 294 patients followed for a median time of 5 years. Acta Orthop 79: 86-93, 2008.

22. Wolfe SW, Mih AD, Hotchkiss RN, Culp RW, Kiefhaber TR and Nagle DJ: Wide excision of the distal ulna: A multicenter case study. J Hand Surg Am 23: 222-228, 1998.

23. Cheng CY, Shih HN, Hsu KY and Hsu RW: Treatment of giant cell tumor of the distal radius. Clin Orthop Relat Res 221-228, 2001.

24. Kang L, Manoso MW, Boland PJ, Healey JH and Athanasian EA: Features of grade 3 giant cell tumors of the distal radius associated with successful intralesional treatment. J Hand Surg Am 35: 1850-1857, 2010.

25. Panchwagh Y, Puri A, Agarwal M, Anchan C and Shah M: Giant cell tumor-distal end radius: Do we know the answer? Indian J Orthop 41: 139-145, 2007.

26. Vander Griend RA and Funderburk $\mathrm{CH}$ : The treatment of giant-cell tumors of the distal part of the radius. J Bone Joint Surg Am 75: 899-908, 1993.

27. Sheth DS, Healey JH, Sobel M, Lane JM and Marcove RC: Giant cell tumor of the distal radius. J Hand Surg Am 20: 432-440, 1995

28. Harness NG and Mankin HJ: Giant-cell tumor of the distal forearm. J Hand Surg Am 29: 188-193, 2004. 